\title{
Entre clausuras, verdades e resistências: a produção do conhecimento acadêmico no contemporâneo
}

\author{
Diego Drescher de Castro, ${ }^{(D)} \star$ Jaqueline Tittoni 1 \\ Universidade Federal do Rio Grande do Sul, Porto Alegre, RS, Brasil
}

Resumo

\begin{abstract}
Este estudo discute alguns elementos para se pensar as relações entre a produção do discurso acadêmico e o lugar da Universidade, a partir da problematização da episteme moderna e da produção da noção de ciência e de conhecimento cientifico. Para tanto, busca principalmente no pensamento foucaultiano subsídios para construir a noção de conhecimento científico como verdade sobre o mundo e a vida, produzidos em relações de poder e de força em disputa. Desta forma, disciplina e controle transversalizam a episteme moderna e se enraizam não só em manicômios e prisões, mas também em instituições de ensino formal, produzindo diferentes tipos de clausura. Se, nas sociedades disciplinares, a clausura se dava sobre o corpo, pode-se dizer que nas sociedades de controle o controle investido nos corpos faz com que esses reproduzam as mais diversas formas de clausura. Sustentar práticas de resistência a partir de reflexões éticas que enfrentem este enclausuramento afirma-se como uma necessidade do contemporâneo.
\end{abstract}

Palavras-chave: verdade; conhecimento; universidade.

\section{Between enclosures, truths and resistances: academic knowledge production in the contemporary}

\begin{abstract}
This study discusses some elements to think the relations between the production of the academic discourse and the place of the University starting from the problematization of the modern episteme and the notion of science and cientific knowledge. To do so, it seeks, in the foucaultian theory, subsidies to build the notion of cientific knowledge as truth about the world and life, produced in relations of power and conflicting forces. Therefore, discipline and control transversalize the modern episteme and take roots not only in asylums and prisions, but also in institutions of formal education, producing different kinds of enclosure. If, in disciplinary societies, enclosure acts over bodies, one can say that in controled societies, the control over bodies makes them reproduce diverse forms of enclosure. Upholding practices of resistance, stemming from ethic thought, to confront such enclosure becomes a contemporary necessity.
\end{abstract}

Keywords: truth; knowledge; university.

\section{Introdução}

Escrever é uma das maiores estratégias de produção de memória e de registro do conhecimento produzido em determinada época. Tais registros e memórias são transmitidos a partir de mitos, tradições, costumes, teorias, crenças, poesias e inúmeras outras formas de expressão. A partir desse vínculo estreito entre escrita e memória, o historiador venezuelano Fernando Báez (2006) nos apresenta aquilo que chama de "memoricídio" no livro intitulado "A história universal da destruição dos livros". Ao longo das páginas, o autor detalha quase cinco mil anos de destruição de livros e incessantes tentativas de apagamento de memória; tentativas de dominação e imposição de um conhecimento tido como verdadeiro em detrimento de outros. Báez (2006, p. 24) defende a teoria de que o livro "é destruído com a intenção de aniquilar a memória que encerra, isto é, o patrimônio de ideias de uma cultura inteira".

Em consonância com a perspectiva apresentada por Baéz, apresenta-se a problematização acerca do caminho unidirecional do saber formal, apresentada por Santos (1997) como algo fundamental nos processos de

\footnotetext{
^Endereço para correspondência: Universidade Federal do Rio Grande do Sul. Rua Ramiro Barcelos, 2600 - Santa Cecília Porto Alegre, RS - Brasil. CEP: 90035-003.E-mail: diegodrescher89@gmail. com, jatittoni@gmail.com

Os dados completos dos autores encontram-se ao final do artigo.
}

colonização. Ao definir o mundo como um "complexo mosaico multicultural" que tem sido balizado por um padrão epistemológico monoculturalista, Santos e Meneses (2008) apresentam o conceito de epistemicídio e sua relação com a modernidade. A partir de uma premissa de avanço científico, delineada em um cenário de apagamento de alguns saberes em detrimento de outros, a lógica colonialista e etnocêntrica é retroalimentada a partir deslegitimação dos saberes localizados.

$\mathrm{Na}$ esteira desse pensamento e entendendo o epistemicídio como ferramenta fundamental para que determinados saberes sejam tomados como verdadeiros, Carneiro (2005, p. 97) afirma que o epistemicídio é "para além da anulação e desqualificação do conhecimento dos povos subjugados, um processo persistente de produção da indigência cultural".

Pode-se dizer que tais análises apontam na mesma direção da produção de Foucault (1995a), quando este diz que a história não tem "sentido". Segundo o autor francês, tal concepção não confere um caráter absurdo ou incoerente à história, mas a possibilidade de compreendê-la para além de lógica vetorial, detentora de um "sentido universal". Foucault (1995a, p. 44) propõe que a historicidade que nos domina é múltipla e não se produz 
a partir de relações de sentido, e sim de relações de poder que "produzem efeitos de verdade no interior de discursos que não são em si nem verdadeiros nem falsos."

Nesse cenário, onde as verdades são entendidas para além de pressupostos dogmáticos e compreendidas em uma complexa trama de relações de poder, destaca-se como marco analítico a transição do século XVIII para o século XIX, período que, segundo Foucault (2000), inaugura a maneira moderna de pensar. Encarar a história como matéria viva, efeito de disputas de poder, é condição fundamental para compreender como alguns discursos sobrepujam outros, principalmente no que diz respeito à constituição de saberes legitimados e verdades históricas. Partindo dessas premissas, e com base na teorização de Michel Foucault acerca da Episteme Moderna, pretende-se abordar nos próximos parágrafos alguns elementos constitutivos das condições de possibilidade que permitiram a produção de conhecimento na contemporaneidade. Refletir sobre estas condições também se mostra como uma forma de problematizar o conhecimento na contemporaneidade como efeito de relações de poder historicamente marcadas pela colonização do próprio pensamento, para além dos processos políticos e econômicos que a constituem.

\section{Episteme moderna e Universidade}

O século XVIII foi "o século do disciplinamento dos saberes", ou seja, a organização dos saberes como disciplina, sendo atribuída a cada disciplina critérios para a classificação dos saberes, exclusão dos "falsos saberes" e "não-saberes", formas de hegemonização e normalização dos conteúdos. Enfim, uma espécie de organização no que diz respeito ao conhecimento produzido até então. Tal organização lançou as bases do que viria a ser chamado de ciência, já que "a ciência não existia antes do século XVIII" (FOUCAULT, 2005, p. 217-218). O autor diz que essa ciência - em oposição às ciências naturais de antes do século XVIII - surge como "policiamento disciplinar dos saberes" e abandona o discurso filosófico, sob a forma de progresso da razão.

É nesse cenário que se colocam as condições de possibilidade para o aparecimento da Universidade moderna na virada do século XVIII para o século XIX. Segundo Foucault (2005, p. 219), surge nesse contexto a Universidade enquanto "grande aparelho uniforme dos saberes", cujo papel é:

essa espécie de monopólio de fato, mas também de direito, que faz que um saber que não nasceu, que não se formou no interior dessa espécie de campo institucional, com limites aliás relativamente instáveis, mas que constitui em linhas gerais a Universidade, os organismos oficiais de pesquisa, fora disso, o saber em estado selvagem, o saber nascido alhures, se vê automaticamente, logo de saída, se não totalmente excluído, pelo menos desclassificado a priori.

Compreender o surgimento das universidades modernas é fundamental para que possamos entender os mecanismos de produção de conhecimento da contemporaneidade. Uma vez que o memoricídio e o epistemicídio têm sido uma constante na produção de conhecimento, urge que nós - pesquisadoras e pesquisadores - possamos fazer a leitura dos jogos de poder que se colocam no curso da história visando sempre à afirmação da dúvida ante às verdades dadas, buscando sempre distanciar conhecimentos de dogmas.

O que se coloca como incômodo, e consequentemente força motriz para a escrita deste artigo, é problematizar o posicionamento de pesquisadoras e pesquisadores acadêmicos diante de um contexto normativo em que, cada vez mais, a lógica de pesquisa nas ciências humanas se aproxima da prática memoricida e epistemicida. Uma prática que, com frequência, reproduz as mesmas premissas para o mesmo público com pouco viés crítico e muito descolamento da realidade vigente, a afirmação unívoca do dogma.

Ora, talvez uma pista para desemaranhar esse problema seja, como propõe Foucault (1995b), tentar compreender uma questão pelo seu negativo. E se a chave para pensar a realidade estiver nas entrelinhas da ficção e do fantástico? De maneira irônica, e questionando a dicotomia verdade/não verdade - ou, ainda mais incisivamente, real/fantasia, o escritor argentino Jorge Luis Borges responde, ao ser interrogado sobre o caráter fantástico de suas obras, que quando alguém escreve uma história sobre o mundo, mesmo que de maneira realística, acaba escrevendo uma história fantástica, porque o mundo em si é fantástico (BORGES, 2011).

Talvez seja justamente essa lente fantástica na maneira de olhar o ser humano que fez com que Foucault buscasse inspiração no escritor portenho para nos introduzir uma de suas obras mais interessantes. De maneira sagaz, quando escreve o prefácio de "As palavras e as coisas", o autor francês se inspira na enciclopédia chinesa apresentada por Borges para lançar as bases daquilo que ele vai tornar a discussão central do livro: as relações do ser humano com as discursividades de determinada época ou, como o próprio autor nos apresenta, "o balizamento dos mecanismos de poder no interior dos próprios discursos científicos: a qual regra somos obrigados a obedecer, em uma certa época, quando se quer ter um discurso científico sobre a vida, sobre a história natural, sobre a economia política?" (FOUCAULT, 2003, p. 226-227).

A enciclopédia apresentada por Borges (2000, p. 77), intitulada de "Empório Celestial de Conhecimentos Benévolos", nos apresenta à frase que talvez tenha inspirado Michel Foucault: "Não há classificação do universo que não seja arbitrária e conjetural". Quando nos exibe a lógica classificatória de tal enciclopédia, Borges (2000, p. 76-77) conta que o volume classificava os animais em diversas categorias, dentre elas algumas pouco usuais para o nosso padrão ocidental, como: (a) pertencentes ao Imperador, (b) embalsamados, (c) amestrados, (d) leitões, (e) sereias, (f) fabulosos, (g) cães soltos, (h) incluídos nesta classificação, (i) que se agitam como loucos, (j) inumeráveis, (k) desenhados com um finíssimo pincel de pelo de camelo.

A classificação - irônica e fantástica, diga-se de passagem - é a base da teorização que Foucault vai tecer a partir da passagem do século XVIII para o século XIX, a passagem da episteme clássica para a episteme moderna. O que o filósofo francês nos apresenta é uma verdadeira 
revolução na lógica de funcionamento das relações e modos de pensar e viver. Para entender o que representa essa passagem de uma episteme para a outra e o porquê da importância de analisarmos isso, é fundamental buscar de que forma é definida episteme:

não é uma forma de conhecimento, ou um tipo de racionalidade que, atravessando as ciências mais diversas, manifestaria a unidade soberana de um sujeito, de um espírito ou de uma época; é o conjunto das relações que podem ser descobertas, para uma época dada, entre as ciências, quando estas são analisadas no nível das regularidades discursivas (FOUCAULT, 2009a, p. 214)

A partir do momento em que as condições de possibilidade de determinada época oferecem as bases necessárias para uma alteração na forma como o ser humano pensa o mundo ao seu redor e, principalmente, como se pensa nesse mundo, surgem as condições para o aparecimento de uma outra episteme. Antes de expor essa maneira moderna de pensar o mundo, Foucault nos apresenta à episteme renascentista, que possuía uma forte ligação com razões cosmológicas, estreitando os laços entre fenômenos naturais, natureza humana e a infinitude (SILVEIRA, 2008).

A passagem para a episteme clássica acontece entre o final do século XVI e o início do século XVII e nos demonstra o deslocamento desse modo de pensar fundado em razões cosmológicas para uma ordem do discurso como representação. Segundo nos mostra Foucault, a Época Clássica é um período no qual está posta uma lógica taxonômica de classificação dos seres da natureza. Se ainda existe o caráter cosmológico em que um Deus aparece como criador, ao ser humano é atribuída a responsabilidade de organizar e classificar essas obras divinas. Segundo Foucault (2000, p. 222), na Idade Clássica "a vida não constitui um limiar manifesto a partir do qual formas inteiramente novas do saber são requeridas. Ela é uma categoria de classificação, relativa, como todas as outras, aos critérios que se fixarem".

Quando trabalha com as características do modo de pensar moderno, Foucault (2000, p. 438) remonta ao início do século XIX para apresentar a transição entre a episteme clássica e a episteme moderna a partir do surgimento do homem enquanto "duplo empírico-transcendental", remetendo ao lugar que este ocupa na episteme. Apresentar o homem como essa figura ambígua, que é, ao mesmo tempo, empírica e transcendental, é apresentar a passagem de um ser que deixa de atuar apenas como observador e classificador, situado num plano externo, para um ser que se coloca tanto como sujeito quanto como objeto dessa discursividade moderna,

e se, por um lado, o homem é simplesmente um meio, uma peça intermediária que atualiza, sedia ou reanima um "já começado", um já começado de um certo tipo de vida, de uma determinada organização produtiva e de regras lingüísticas específicas, por outro lado, não se pode negar que ele é princípio dessa vida, desse trabalho e dessa língua que nele se atualizam (NOTO, 2011, p. 78).
Ressaltamos que, por mais que se trabalhe com o conceito de episteme moderna e com a figura da "passagem" de uma episteme para outra, não se pode afirmar a extinção da episteme clássica. Ainda que permeados por uma relação com a episteme moderna, diversos instrumentos criados pela lógica disciplinar correspondem a uma lógica clássica. Se pensarmos nos manuais diagnósticos utilizados pela psiquiatria, por exemplo, pode-se dizer que são utilizados em um contexto marcado pela lógica disciplinar operando nos corpos, porém tem sua escrita sistemática e classificatória ancorada em uma maneira de pensar que remete à episteme clássica. Assim, podemos recorrer a Foucault, quando o autor propõe que não tomemos a modernidade unicamente como uma época, ou o conjunto de traços que determina uma época, mas a partir de uma atitude moderna, ou seja, um ethos filosófico como crítica, "uma maneira de pensar e sentir, uma maneira também de agir e de se conduzir que, tudo ao mesmo tempo, marca uma pertinência e se apresenta como uma tarefa" (FOUCAULT, 2012).

Ainda que Foucault (apud DREYFUS; RABINOW, 1995, p. 30) não explique o que permitiu o aparecimento da episteme moderna, ele aponta que, a partir dessa abrupta separação, o homem não se reconhece mais em um mundo pautado por uma organização divina ou ao lado dos animais no quadro da história natural.

O homem, que era um ser entre outros, torna-se agora um sujeito entre objetos. Mas ele não é apenas sujeito entre objetos; ele logo entende que aquilo que tenta compreender não são apenas os objetos do mundo, mas a si mesmo. Ele se torna o sujeito e o objeto de seu conhecimento. Agora, o homem está limitado pelo seu envolvimento com uma linguagem que não é mais um suporte transparente, mas uma densa rede com uma história própria. O sujeito cognoscente, por estar envolvido com a linguagem, sem um campo de luz que permita um acesso direto à estrutura dos objetos $\mathrm{e}$ do mundo, não é mais um puro espectador.

$\mathrm{Na}$ sua teorização sobre a episteme moderna, Foucault nos apresenta as bases para uma nova discursividade sobre o sujeito, a qual se torna objeto de estudo para o autor, a fim de entender porque determinados discursos são aceitos como verdadeiros em detrimento de outros. Ao trilhar esse percurso, Foucault percebe que a produção de verdades, ainda que ambientada em um contexto ocidental de episteme moderna, se produz para além da ordem discursiva (CASTRO, 2004).

\section{Episteme moderna e microfísica do poder}

Essa episteme moderna apresentada por Foucault atualiza as condições para que determinados discursos sejam encarados como verdadeiros ou não, ou seja, incide diretamente no campo do saber a partir de técnicas e condições que permitem ou não que determinadas proposições entrem no campo da verdade, constituindo o conceito de disciplina. $\mathrm{O}$ autor aponta que "uma disciplina se define por um domínio de objetos, um conjunto de métodos, um corpus de proposições consideradas verdadeiras, um jogo de regras e de definições, de técnicas e de instrumentos" (FOUCAULT, 1996). 
O uso discursivo do conceito de disciplina apontado por Foucault prepara o terreno para um dos eixos centrais da obra do autor: a relação entre saber e poder. Ao ser questionado sobre o teor da sua pesquisa, Foucault (2003, p. 229) diz que seu foco é pesquisar os efeitos de verdade que uma sociedade produz a cada instante. Segundo o autor, tais produções não podem ser dissociadas de mecanismos de poder que as induzem. A partir dessa tensão verdade/poder, e, por consequência, saber/poder, Foucault (2009b, p. 30) vai deslocar a análise do poder de uma noção de soberania e dominação para um lugar estratégico, onde se encontram todas as relações saber/ poder. Segundo o autor,

não há relação de poder sem constituição correlata de um campo de saber, nem saber que não suponha e não constitua ao mesmo tempo relações de poder. Essas relações de "poder-saber" não devem então ser analisadas a partir de um sujeito do conhecimento que seria ou não livre em relação ao sistema do poder; mas é preciso considerar ao contrário que o sujeito que conhece, os objetos a conhecer e as modalidades de conhecimentos são outros tantos efeitos dessas implicações fundamentais do poder-saber e de suas transformações históricas. Resumindo, não é a atividade do sujeito de conhecimento que produziria um saber, útil ou arredio ao poder, mas o poder-saber, os processos e as lutas que o atravessam e que o constituem, que determinam as formas e os campos possíveis do conhecimento (FOUCAULT, 2009b, p. 30)

Pode-se dizer que, para Foucault (2009b, p. 29), o poder aparece como uma microfísica posta em jogo pelos aparelhos e instituições e que atua sobre os corpos. Conceber o poder enquanto microfísico é dizer que ele "mais se exerce do que se possui”, que não é um privilégio que se possa transferir, mas efeito de posições estratégicas. Essa concepção tira do poder o caráter do "tudo ou nada", sua condição unívoca, criando, ao mesmo tempo, inúmeras formas de opressão e inúmeros focos de luta e possibilidades de resistência. Ao tirar do poder o caráter unicamente repressivo, se criam as condições para que se pense o poder como força produtiva, uma vez que permeia todo o tecido social (FOUCAULT, 1995a).

Dito isto, pode-se concluir que a gama de condições que acaba culminando em práticas memoricidas e epistemicidas e, consequentemente, na criação de verdades-dogma não é mais fruto exclusivo de uma opressão vertical e unilateral exercida por um soberano (como acontecia na Idade Média, por exemplo), mas sim de uma rede microfísica, ramificada e multifacetada de poderes que se entranha em todo corpo social. Duarte (2008, p. 67), ao analisar a obra do autor francês, nos aponta que

Foucault não concebe o poder nem como violência legalizada nem como a violência que escapa à lei, pois, segundo suas análises, as relações de poder não se constituem na base das relações legais, no nível do Direito e dos contratos, mas sim no plano das disciplinas e de seus efeitos de normalização e moralização. Em poucas palavras, o que Foucault havia descoberto não era a impotência ou inoperância do poder soberano, mas sim a maior eficácia de um conjunto de poderes que, em vez de negar e reprimir, atuavam discretamente na produção de realidades e efeitos desejados por meio de processos disciplinares e normalizadores.

A leitura que se pode fazer a partir do percurso teórico desenvolvido pelo autor é que a virada da episteme clássica para a episteme moderna na passagem do século XVIII para o século XIX contribui de maneira decisiva para a concepção do poder como microfísico. As monarquias da época clássica não foram responsáveis somente por constituir grandes mecanismos que viriam a ser fundamentais para a constituição dos estados, como exército e administração local, mas também porque "instauraram o que se poderia chamar uma nova 'economia' do poder, isto é, procedimentos que permitem fazer circular os efeitos de poder de forma ao mesmo tempo contínua, ininterrupta, adaptada e 'individualizada' em todo o corpo social” (FOUCAULT, 1995a).

Foucault propõe uma forma de pensar as relações de poder de maneira mais próxima a nossa situação contemporânea, que implica vínculos mais estreitos entre teoria e prática. $\mathrm{O}$ autor apresenta uma metáfora e sugere que pensemos o poder a partir das resistências que se opõem a ele, comparando-as a um catalisador químico, a fim de "esclarecer as relações de poder, localizar sua posição, descobrir seu ponto de aplicação e os métodos utilizados" (FOUCAULT, 1995b, p. 234). Ao indicar que analisemos o poder a partir do antagonismo de suas estratégias, Foucault sugere, por exemplo, que, para pensar a sanidade, investiguemos a loucura, para problematizar a legalidade, tomemos a ilegalidade.

O poder, a partir da lógica disciplinar, encontra no corpo um campo de batalha. As verdades científicas se sustentam até hoje, firmes e fortes, porque localizam no corpo as condições de possibilidade para exercer o poder, num eterno jogo de retroalimentação, no qual o corpo que é investido pela ciência é o plano que cria as condições para a legitimação desses jogos de poder. Ao situar o posicionamento ético de tomar o poder a partir da resistência, Foucault nos mostra que o que interessa enquanto luta ante as verdades legitimadas não é enfrentar um poder determinado, mas sim enfrentar uma técnica de poder. Dessa maneira, o autor lança as bases para pensar num corpo que, ao mesmo tempo em que é investido, resiste ao poder.

\section{Clausura, controle e resistência}

Presença constante nas análises filosóficas ocidentais, a partir do século XIX a clausura assume um papel recorrente na obra de Michel Foucault. Pode ser compreendida a partir das condições de possibilidade que surgem na episteme moderna, mas, ao mesmo tempo, se atualiza para além da discursividade da episteme, assumindo o caráter de dispositivo disciplinar. Tal conceito é definido por Foucault (1995a, p. 244) como

um conjunto decididamente heterogêneo que engloba discursos, instituições, organizações arquitetônicas, decisões regulamentares, leis, medidas administrativas, enunciados científicos, proposições filosóficas, morais, filantrópicas. Em suma, o dito e o não dito são os elementos do dispositivo. O dispositivo é a rede que se pode estabelecer entre estes elementos. 
A partir do momento em que o conjunto de métodos vinculados a um saber específico encontra em uma instituição total as condições de possibilidade para incidir nos corpos, percebe-se uma atualização do conceito de disciplina. Passa a ser, então, uma "série de métodos que permitem o controle minucioso das operações do corpo, que realizam a sujeição constante de suas forças e lhe impõe uma relação de docilidade-utilidade [...]" (FOUCAULT, 2009b, p. 133).

Assim, quando Foucault (2013) nos apresenta em suas obras o início do encarceramento da loucura e detalha a incorporação dos presídios pela lógica jurídica e institucionalização do castigo através dos muros da prisão (FOUCAULT, 2009b), fica mais aparente essa associação entre episteme moderna, microfísica do poder e clausura.

Baseado na pesquisa de Foucault sobre as sociedades disciplinares, Deleuze (2010) nos diz que estas se situaram entre os séculos XVIII e XIX, tendo seu apogeu no século XX. Centrada na lógica de indivíduos que não cessam de passar de um espaço fechado a outro, tal lógica de sociedade encontra nas prisões seu meio de confinamento por excelência. Porém, a partir do fim da Segunda Guerra Mundial, Deleuze aponta que a sociedade entra em um processo de transição - que ainda vivemos - no qual começa a deixar de ser disciplinar, graças a uma crise generalizada em todas as organizações de confinamento.

O espaço disciplinar, encerrado entre paredes, vem sendo substituído por uma lógica de controle que, justamente por se dar em meio aberto e se reinventar ininterruptamente, dificulta sua localização.

Nas sociedades de disciplina não se parava de recomeçar (da escola à caserna, da caserna à fábrica), enquanto nas sociedades de controle nunca se termina nada, a empresa, a formação, o serviço sendo os estados metaestáveis e coexistentes de uma mesma modulação, como que de um deformador universal (DELEUZE, 2010, p. 225-226).

Se na sociedade disciplinar o saber produzia argumentos para um disciplinamento dos corpos, hoje o controle produzido sobre os corpos produz o conhecimento que vai ser investido, retroalimentando essa lógica. Dessa forma, a produção de conhecimento memoricida e epistemicida - logo, também hegemônica - bem como seus mecanismos de controle tendem a constituir pesquisadoras e pesquisadores docilizados, que fazem girar a engrenagem que impõe verdades como dogmas.

Nesse sentido, disciplina e controle transversalizam a episteme moderna e, a partir de jogos de verdade e relações de poder, se enraízam não só em manicômios e prisões, mas também em instituições de ensino formal, produzindo diferentes tipos de clausura. Se nas sociedades disciplinares a clausura se dava sobre o corpo, pode-se dizer que nas sociedades de controle o controle investido nos corpos faz com que estes reproduzam as mais diversas clausuras.

Deleuze (2010a, p. 226) diz que as sociedades disciplinares "têm dois polos: a assinatura que indica o indivíduo, e o número de matrícula que indica sua posição numa massa", ao mesmo tempo que é massificante é in- dividuante. Já a lógica de controle é expressa em cifras, justamente para dar a dimensão das constantes modulações, pautando-se principalmente pela medida de acesso ou exclusão à informação. Segundo o autor, a lógica disciplinar é a moeda de ouro: uma medida padrão e universal; o controle é o dinheiro, suscetível às flutuações e modulações do mercado.

Partindo dessa construção, entende-se a produção de verdades absolutas não como algo imposto, mas como território em disputa constante no contexto da sociedade de controle. Assim sendo, não se trata de condenar ou deslegitimar a produção científica realizada nas universidades; a aposta é que se transforme a ciência em território de disputa, de fato. Entender que a Universidade contemporânea - enquanto principal organização que sustenta o saber científico - é, como qualquer outra organização, palco de embates éticos e políticos que produzem verdades.

A concepção microfísica do poder cria as condições de possibilidade para estratégias de resistência dentro da lógica massiva de produção de subjetividade. Assim, é importante considerar essa estratégia como uma guerrilha que, compreendendo seu caráter menor, pode se colocar enquanto luta frente à lógica dominante. A proposição de luta para Foucault surge a partir da concepção de sua obra como uma "filosofia analítica do poder" (CASTRO, 2004). Para o autor, tal filosofia consiste em tornar visível aquilo que é visível, "analisar as forças que constituem nosso presente". Assim, Foucault apresenta seu conceito de luta a partir de quatro pontos principais: 1) não se deve tomar o poder de maneira massiva ou global, mas sim compreender este enquanto jogos, em termos de táticas e estratégias; 2) as lutas são fenômenos descentrados, que partem de problemas mais específicos e locais; 3 ) tais lutas têm por objetivo os efeitos do poder e sua forma concreta de exercício; 4) por último, são lutas imediatas (CASTRO, 2004).

Por mais que essas clausuras transversalizem a episteme moderna, Foucault $(1984$, p. 342) propõe que não tomemos a modernidade unicamente como uma época, ou o conjunto de traços que determina uma época, mas a partir de uma atitude moderna, ou seja, um ethos filosófico como crítica, "uma maneira de pensar e sentir, uma maneira também de agir e de se conduzir que, tudo ao mesmo tempo, marca uma pertinência e se apresenta como uma tarefa". O que Foucault (1984, p. 3) lança com a proposição de uma atitude moderna frente às problemáticas que emergem com a nova episteme é uma aposta num modo de vida que se produza a partir da relação entre ética e liberdade; afinal, "o que é a ética senão a prática da liberdade, a prática refletida da liberdade".

$\mathrm{O}$ caráter reflexivo que se impõe à noção de práticas de liberdade, atribuindo-lhes um lugar fundamental na discussão sobre a ética, implica uma atitude de problematização dos modos de vida e de seus efeitos de poder e de subjetivação. A pergunta sobre o presente, sobre seus efeitos nos modos como nos produzimos e reconhecemos como sujeitos e sobre as verdades que se impõem aos modos de conduzir a vida, segue como uma força viva a mobilizar uma conduta ética e reflexiva nos tempos que chamamos de nossos.

Fractal, Rev. Psicol., v. 31 - n. 3, p. 298-304, 2019 
Foucault discute a relação entre as formas do saber e as forças do poder, mas Deleuze (2005), ao falar sobre Foucault, enfatiza o olhar do autor sobre o que chama de "processos de si", se referindo a uma relação de si para consigo mesmo, que se produz nas relações saber-poder. Foucault diz que esse processo também é uma relação de forças consigo, ao passo que o poder é uma relação de força com outras forças, ou seja, isso que vai ser chamado de processo de subjetivação, essa relação de forças consigo, é uma dobra da linha de forças (do poder) para si mesmo. É um processo ético que produz essa dobra no sentido de constituição de modos de existência e invenção de possibilidades de vida, "não a existência como sujeito, mas como obra de arte" (DELEUZE, 2010b, p. 120). Deste modo, as relações entre saber e poder acabam por converter-se em relações entre o sujeito e as verdades que o produzem, a partir de uma posição ética.

A partir do percurso teórico aqui proposto, se concebemos o poder como multifacetado e polimorfo e em constante disputa, compreendemos que assumir uma posição ética de crítica ante as verdades instituídas surge como estratégia de resistência ao enclausuramento, seja ele de um manicômio, uma prisão ou da ciência.

\section{Considerações finais}

A discussão aqui proposta teve como objetivo pensar alguns elementos que articulam a produção da episteme moderna com os modos de configuração do discurso acadêmico e científico. A escrita, sempre em débito com a experiência cotidiana, faz do final de um texto um momento de reconhecimento de algumas sistematizações e a evidência de outras tantas questões que se abrem a partir dele. Nesta temática, sobretudo, os efeitos dos estudos descoloniais na produção acadêmica e científica abrem outras linhas de força que estão a redefinir resistências e jogos de poder neste campo. Os temas da racialização do conhecimento e da criação de uma epistemologia feminista, como exemplos mais evidentes, mostram que a discussão sobre a racionalidade acadêmica e científica encontra-se em momento de grandes movimentos. A crítica ao colonialismo, centrado no modelo de homem branco, está produzindo a emergência de autores africanos e latino-americanos na cena da disputa pelo conhecimento, redefinindo a centralidade do pensamento europeu. Estes temas, com certeza, poderão provocar uma releitura desta escrita e forçá-la a desdobrar-se em outras reflexões e críticas a partir da conduta ética aqui formulada.

Assim, pode-se tomar a ideia central desta proposta, a saber, sustentar práticas de resistência a partir de novas formas de lidar com a verdade, como eixo que se mantém a partir das problematizações contemporâneas. Práticas de resistência que possam encarar a produção de conhecimento como campo de batalha e se coloquem enquanto reativas aos processos de exclusão próprios da sociedade de controle. Uma produção de conhecimento que se baseie cada vez mais na ética do comum e menos nas imposições de uma produção de conhecimento pautada por práticas memoricidas e epistemicidas.

\section{Informações sobre os autores:}

Diego Drescher de Castro

iD https://orcid.org/0000-0003-2442-8696

(9) http://lattes.cnpq.br/8653672706195582

Psicólogo, graduado pelo Instituto de Psicologia da Universidade Federal do Rio Grande do Sul (UFRGS). Mestre em Psicologia pelo Programa de Pós-Graduação em Psicologia Social e Institucional (UFRGS). Atualmente cursando doutorado pelo Programa de PósGraduação em Psicologia Social e Institucional (UFRGS). Tem experiência nas áreas da Psicologia Social, Análise Institucional, Acompanhamento Terapêutico, Educação Popular, Segurança Pública, Desinstitucionalização, Clínica Ampliada, Filosofia da Diferença.

Jaqueline Tittoni

iD https://orcid.org/0000-0002-3450-080X

(9) http://lattes.cnpq.br/5539072466903999

Possui graduação em Psicologia pela Pontifícia Universidade Católica do Rio Grande do Sul (1986), mestrado em Sociologia pela Universidade Federal do Rio Grande do Sul (1992) e doutorado em Sociologia pela Universidade Federal do Rio Grande do Sul (1999). Realizou estágio de pós-doutorado no master em Psicologia Social da Universidade Autônoma de Barcelona (2005-2006) Atualmente é professora adjunto da Universidade Federal do Rio Grande do Sul. Tem experiência na área de Psicologia, com ênfase em Fatores Humanos no Trabalho, atuando principalmente nos seguintes temas: trabalho, subjetividade, saúde mental e fotografia.

\section{Contribuições dos autores:}

Todos os autores colaboraram ao longo do processo, desde a elaboração até a revisão final do manuscrito. Os autores aprovaram o manuscrito final para publicação.

\section{Como citar este artigo:}

\section{ABNT}

CASTRO, Diego Drescher de; TITTONI, Jaqueline. Entre clausuras, verdades e resistências: a produção do conhecimento acadêmico no contemporâneo. Fractal: Revista de Psicologia, Niterói, v. 31, n. 3, p. 298-304, set./dez. 2019. https://doi.org/10.22409/1984-0292/ v31i3/5627

\section{APA}

Castro, D. D., \& Tittoni, J. (2019, Setembro/Dezembro). Entre clausuras, verdades e resistências: a produção do conhecimento acadêmico no contemporâneo. Fractal: Revista de Psicologia, 31(3), 298-304. doi: https://doi.org/10.22409/1984-0292/v31i3/5627

\section{Referências}

BÁEZ, Fernando. História universal da destruição dos livros: das tábuas sumérias à guerra do Iraque. Rio de Janeiro: Ediouro, 2006.

BORGES, Jorge Luis. O idioma analítico de John Wilkins. In: . Outras inquisições. São Paulo: Globo, 2000. p. 92-95.

BORGES, Jorge Luis. Jorge Luis Borges. In: REVIEW, Paris (Ed.). As entrevistas da Paris Review. Tradução de Christian Schwartz e Sérgio Alcides. São Paulo: Companhia das Letras, 2011. v. 1, p. 120-176.

CARNEIRO, Aparecida Sueli. A construção do outro como não-ser como fundamento do ser. 2005. Tese (Doutorado em

Educação) -Universidade de São Paulo, São Paulo, 2005.

CASTRO, Edgardo de. El vocabulario de Michel Foucault. Buenos Aires: Prometeo, 2004.

DELEUZE, Gilles. Foucault. Lisboa: Edições 70, 2005. 
DELEUZE, Gilles. Post-Scriptum sobre as sociedades de controle. In: Conversações. São Paulo: Ed. 34, 2010a. p. 223-230.

DELEUZE, Gilles. Rachar as coisas, rachar as palavras. In: Conversações. São Paulo: Ed. 34, 2010b. p. 109-121.

DREYFUS, Hubert; RABINOW, Paul. Michel Foucault, uma trajetória filosófica: para além do estruturalismo e da hermenêutica. Rio de Janeiro: Forense Universitária, 1995.

DUARTE, André de Macedo. De Michel Foucault a Giorgio Agamben: a trajetória do conceito de biopolítica. In: SOUZA, Ricardo Timm de; OLIVEIRA, Nythamar Fernandes de (Org.). Fenomenologia hoje III: Bioética, Biotecnologia, Biopolítica. Porto Alegre: Edipucrs, 2008. p. 63-87.

FOUCAULT, Michel. O que são as luzes. In: MOTTA, Manoel Barros da (Org.). Arqueologia das ciências e história dos sistemas de pensamento. Rio de Janeiro: Forense Universitária, 1984. Coleção Ditos \& Escritos, v. 2, p. 335-351.

FOUCAULT, Michel. Microfisica do poder. Rio de Janeiro: Graal, 1995a.

FOUCAULT, Michel. O Sujeito e o Poder. In: DREYFUS, Hubert; RABINOW, Paul. Michel Foucault, uma trajetória filosófica: para além do estruturalismo e da hermenêutica. Rio de Janeiro: Forense Universitária, 1995b. p. 231-249.

FOUCAULT, Michel. A Ordem do discurso. São Paulo: Loyola, 1996.

FOUCAULT, Michel. As palavras e as coisas. São Paulo: Martins Fontes, 2000.

FOUCAULT, Michel. Estratégia, Poder-Saber. Rio de Janeiro: Forense Universitária, 2003. Coleção Ditos \& Escritos, v. 4.

FOUCAULT, Michel. Em defesa da sociedade. São Paulo: Martins Fontes, 2005.

FOUCAULT, Michel. A Arqueologia do saber. Rio de Janeiro: Forense Universitária, 2009a.

FOUCAULT, Michel. Vigiar e punir. Petrópolis, RJ: Vozes, $2009 b$.

FOUCAULT, Michel. A ética do cuidado de si como prática da liberdade. In: MOTTA, Manoel Barros da (Org). Ética, sexualidade e política. Rio de Janeiro: Forense Universitária, 2012. Coleção Ditos \& Escritos, v. 5, p. 264-287.

FOUCAULT, Michel. História da loucura na idade clássica. São Paulo: Perspectiva, 2013.

NOTO, Carolina de Souza. Da ilusão transcendental à ilusão antropológica: Foucault em defesa de Kant. Cadernos de Ética e Filosofia Política, n. 18, p. 73-88, 2011. Disponível em: http://www.revistas.usp.br/cefp/article/view/55723. Acesso em: jan. 2017.

SANTOS, Boaventura de Souza. Uma concepção multicultural de direitos humanos. Lua Nova: Revista de Cultura e Política, São Paulo, n. 39, p. 105-124, 1997. http://dx.doi.org/10.1590/ S0102-64451997000100007

SANTOS, Boaventura de Souza; MENESES, Maria Paula. Epistemologias do Sul. Revista Crítica de Ciências Sociais, Coimbra, Portugal, n. 80, p. 11-43, 2008.
SILVEIRA, Fernando de Almeida. Michel Foucault e a construção discursiva do corpo do sujeito moderno e sua relação com a psicologia. Psicologia em Estudo, Maringá, v. 13, n. 4, p. 733-742, dez. 2008. http://dx.doi.org/10.1590/ S1413-73722008000400011 